19 Revue d'histoire du XIXe siècle

Société d'histoire de la révolution de 1848 et des

révolutions du XIXe siècle

$47 \mid 2013$

Quel est l'avenir du XIX $X^{\mathrm{e}}$ siècle ?

\title{
Notes sur Musset
}

\section{Benoît Lambert}

\section{OpenEdition \\ Journals}

Édition électronique

URL : http://journals.openedition.org/rh19/4541

DOI : $10.4000 /$ rh 19.4541

ISSN : $1777-5329$

Éditeur

La Société de 1848

Édition imprimée

Date de publication : 31 décembre 2013

Pagination : 37-39

ISSN : 1265-1354

Référence électronique

Benoît Lambert, " Notes sur Musset », Revue d'histoire du XIXe siècle [En ligne], 47 | 2013, mis en ligne le 31 décembre 2016, consulté le 03 mai 2019. URL : http://journals.openedition.org/rh19/4541 ; DOI : $10.4000 /$ rh19.4541 


\section{BENOÎT LAMBERT}

\section{Notes sur Musset}

Je ne suis pas sûr d'avoir grand-chose à dire sur ce qu'il "reste" du $\mathrm{XIX}^{\mathrm{e}}$ siècle. Très clairement, je n'ai aucune idée sur la question. Mais j’ai toujours aimé Musset, en tout cas depuis l'adolescence. J'ai dû lire Un spectacle dans un fauteuil en classe de première. Et puis il y a eu aussi, la même année (1986 ?), la magistrale mise en scène d'On ne badine avec l'amour par JeanPierre Vincent. Une révélation! Si je devais nommer un spectacle à l'origine de mon désir de théâtre, ce serait sans doute celui-là.

Pourquoi Musset? C’est difficile à dire... À cause du mélange des genres, sans doute : j'étais absolument fasciné par ce théâtre qui permettait de rire et de pleurer en même temps, qui semblait toujours déchirant et léger. À tel point que j'ai parfois l'impression que les pièces de Musset sont celles qui accomplissent le mieux le projet romantique dans le domaine du théâtre : briser les codes classiques, retrouver une liberté. Pour cela, c'est toujours intéressant de monter Musset. La nouveauté, la provocation, presque, que constitue son théâtre (qu'il écrivait précisément pour qu'il ne soit pas joué), tout cela reste très excitant à traiter, même après les révolutions successives traversées par l'art théâtral dans la suite du XIX' siècle comme dans le cours du XXe siècle.

En même temps c'est bizarre, car à l'époque où j'ai un peu fréquenté les cours de théâtre, Musset avait encore mauvaise réputation : trop languissant, trop bien élevé, trop verbeux, légèrement ennuyeux. Quand on l'abordait, d'ailleurs, on avait beaucoup de mal à se débarrasser des clichés éculés qui devaient nous sembler "romantiques» : soupirer, faire le beau, regarder dans le vague, beaucoup souffrir. Ce genre de sottises. Adolescent, on adorait ça, même si on comprenait bien que ça ne marchait pas, que ce théâtre-là ne pouvait pas être joué comme ça.

Ensuite, il y a eu la découverte de la Confession d'un enfant du siècle: "Alors s'assit sur un monde en ruine une jeunesse soucieuse..." J'ignore au juste de quand date l'idée de génération dans la pensée et dans la littérature française. Mais le portrait de la "génération 1830 » fait par Musset au début de la Confession a constitué pour moi une clé de lecture essentielle 
pour analyser la situation de notre génération à la fin du siècle dernier : nous, les «enfants de 68 », nés au tout début des années 1970, qui avions grandi dans le reflux des idéaux révolutionnaires des «années de poudre» et dans la déception de l'expérience socialiste inaugurée en 1981, n'étions-nous pas les lointains descendants des ces jeunes gens perdus dans la France de la Restauration, qui regardaient avec mélancolie les exploits de leurs pères, qui avaient eux connu 1789 et les conquêtes de l'Empire? Dans un spectacle créé en 1999, intitulé La conversation interrompue, dans lequel nous nous efforcions de faire le point sur notre situation politique dix ans après la chute du Mur, j'avais glissé en guise de conclusion les premières pages de la Confession: "[...] notre siècle présent, en un mot, où l'on ne sait, à chaque pas qu'on fait, si l'on marche sur une semence ou sur un débris [...]" Clairement, c'était de nous que Musset parlait, et notre mélancolie n'avait rien à envier à la sienne. Surtout, Musset nous permettait d'affirmer et de revendiquer notre jeunesse : nous étions, comme ses personnages, victimes des temps et des renoncements de nos aînés, nous étions jeunes et désenchantés, comme Fantasio, comme Lorenzo, comme Octave, comme Marianne, comme Perdican, comme Camille...

Je mesure bien, avec le recul, ce que ce type de rapprochement ou d'identification pouvait avoir de factice. C'est amusant d'ailleurs, car maintenant que j'ai (un peu) vieilli et que je me rapproche doucement de l'âge auquel Musset est mort, je découvre souvent dans les spectacles des jeunes compagnies théâtrales cette même rhétorique de la jeunesse et du désenchantement, héritée du romantisme. Je sais bien aujourd'hui que la pensée en termes de génération, si réconfortante soit-elle parfois dans la mesure où elle permet à chaque génération de présenter comme absolument inédit (et dramatique, forcément) le contexte historique dans lequel elle est appelée à grandir et à agir, reste malgré tout une pensée faible. Comme disait Bourdieu, «la jeunesse n'est qu'un mot» et les proximités générationnelles n'annulent jamais les différences de classes. À cet égard, il ne devait pas y avoir beaucoup de points communs en 1830 entre un poète romantique parisien et un jeune paysan de Bourgogne ou du Berry. Et cette nuance de taille, sans doute, était encore valable "toutes choses égales par ailleurs" en 1999. Bien sûr... Cela ne retire rien au fait que Musset, et le moment historique qu'il symbolise, ont été pour nous une puissante source d'inspiration. Que nous nous sommes éprouvés comme «jeunes" à travers lui.

J'ai monté à ce jour trois pièces de Musset: Lorenzaccio en 1998 puis douze ans plus tard, Fantasio et Badine en diptyque, sous le titre Enfants du Siècle. Chaque fois, j'ai trouvé cela très passionnant et très difficile. Question de style, ou de ton. Pour les acteurs, l'enjeu est souvent de (re)trouver un mouvement, une rage derrière la littérature ou le poème, derrière l'intimidation du "beau langage». Il y a une petite musique qu'il faut briser, certaines postures du corps, héritées des classes d'art dramatique, mais aussi des 
traditions d'interprétation instaurées par la Comédie Française à la fin du $\mathrm{XIX}^{\mathrm{e}}$ siècle, qui ont contribué à beaucoup édulcorer Musset. Il faudra quasiment attendre Jean-Pierre Vincent dans les années 1980 pour que ses pièces retrouvent toute leur vitalité, toute leur tension.

C'est d'autant plus étonnant que lorsqu'on regarde de près sa biographie, on constate qu'au fond Musset se rapproche plutôt de Rimbaud, pour la destinée littéraire. Ou de Kurt Cobain. Sa période d'inspiration est relativement courte, et pour ce qui est du théâtre, il écrit l'essentiel de son œuvre entre 20 et 25 ans, à un rythme incroyable. Ensuite, c'est comme si son inspiration était tarie. Ce qu'il écrit est bien moins intéressant, et explique sans doute le malentendu, pour ne pas dire la récupération qui s'organise autour de son œuvre. Ce sont en effet les pièces les plus faibles et les plus tardives, celles dans lesquelles Musset fait l'apologie du mariage, de la fidélité et de la vie bourgeoise, qui seront jouées les premières à la Comédie Française. À ce moment là, le débauché révolté et incandescent de 1830 n'est plus qu'un alcoolique épuisé qui ambitionne d'entrer à l'Académie. Triste destinée pour un rebelle... À tout prendre, mieux vaut sans doute aller vendre des armes en Abyssinie.

En revanche on reste confondu par l'énergie, l'insolence, la violence presque, de ses premières pièces. Badine, notamment, qui est sans doute son chef d'œuvre, n'est pas du tout la pièce languissante et sentimentale à laquelle on la réduit parfois : c'est un réquisitoire brûlant contre le patriarcat et le pouvoir religieux. C'est le cri rageur d'une jeunesse qui étouffe sous le poids des traditions et des obligations. Cette brutalité de l'œuvre de Musset résonne comme à rebours avec d'autres cris, d'autres protestations lancées depuis par la jeunesse, des barricades de 1830 jusqu'à celles de 1968 ou jusqu'au mouvement punk. Et on peut s'attendre à l'entendre résonner à l'avenir avec d'autres cris, d'autres indignations. C'est ce qui lui permet de perdurer, et qui fait qu'elle a sans doute un bel avenir devant elle...

Benoît Lambert est metteur en scène et dramaturge; il dirige le Théâtre Dijon Bourgogne - Centre dramatique national 